Review

\title{
Anxiety-related circuitry in affective neuroscience
}

\author{
Lleuvelyn A. Cacha ${ }^{1, *}$, Roman R. Poznanski², Sheikh Hussain Salleh ${ }^{3}$, Ahmad Zubaidi Abdul Latif ${ }^{4}$ and Tengku M. Ariff ${ }^{4}$ \\ ${ }^{1}$ Faculty of Medicine and Health Sciences, Universiti Sultan Zainal Abidin, Kuala, 21300 , Terengganu, Malaysia \\ ${ }^{2}$ Faculty of Informatics and Computing, Universiti Sultan Zainal Abidin, Besut Campus, Kuala Terengganu, 22200, Malaysia \\ ${ }^{3}$ Centre for Biomedical Engineering, Universiti Teknologi Malaysia, Johor Bahru, 81310 , Malaysia \\ ${ }^{4}$ Faculty of Medicine, Universiti Sultan Zainal Abidin, Kuala Terengganu, 21300, Malaysia \\ *Correspondence: Icacha@unisza.edu.my (Lleuvelyn A. Cacha)
}

DOI: $10.31083 /$ i.jmcm.2020.03.806

This is an open access article under the CC BY 4.0 license (https://creativecommons.org/licenses/by/4.0/).

We review the neurological bases of emotions and anxiety-related behavior, integrating contributions from the medical, biological, cognitive neuroscience, and psychological sciences. In particular, we discuss recent affective neuroscience of anxiety-related neurological circuits and metabolic-neuroendocrine systems and their dynamic interaction. This interaction is a delicate process during which can render the brain more capable of reacting to anxiety in adaptive or maladaptive into the most critical deficit in emotional regulation associated with risk for psychopathological conditions. The essence of this associated risk involves the reciprocal influence between hypothalamic-pituitary-adrenal function, the relay nucleus within the amygdala reactivation, and the hippocampus as essential structures associated with the forebrain pathways mediating threat-induced hormones and the $\gamma$ aminobutyric acid neurotransmitter system as central to the regulation of anxiety. To understand how related emotional experience occurs on the neural level and its impact on cognition and behavior requires mapping the multi-step process of the hypothalamic-pituitary-adrenal axis and the hormones released by each of these structures through interactions between threat-sensitive brain circuitry and the responsivity of neuroendocrine fear-system.

\section{Keywords}

Affective neuroscience; amygdala; anxiety disorder; emotion control and regulation; fear responses; neural circuitry; stress hormones

\section{Introduction}

Affective neuroscience involves the dynamic interplay of multi-level brain interactions associated with generating emotional experience parallel with cognitive processes that are perceived to have a substantial influence on behavioral intents [1]. Individual affective states are likely to evolve converging on complex neural dynamics of emotions that need to be conceptualized and consciously linked to the multicomponent of cognitive processes from which they emerge as adaptive responses in anticipation of stimuli that threaten to disturb homeostasis $[2,3,4,5]$. The brain mechanism of affect underlying perception and cognitive appraisal of a situation is likely to activate specific brain circuits that instigate to affective experience related to the behavioral responses associated with fear and anxiety [6, 7]. Collectively, these mental representations of the interpreted context on the subjective quality of affective states are an essential contributor to future emotional and behavioral tendencies [8,9]. This behavioral experience accompanies spontaneous physiological and emotional reactions. Steimer (2002) identified that these reactions which are associated with emotions, ultimately facilitate adaptive responses to environmental challenges and boost memory presentation, to a certain extent enabling the famous "fight or flight" reaction. The human brain and its context-dependent response functions, including cross-level integration of signalling structures and circulating hormones, are sophisticated and flexible. The study of Raz et al. (2012) examined emotions emerging from the neurodynamics of many interacting brain systems, like how neurons behave in relations to emotions can have a substantial influence on cognitive processes and impact different systems that have specialized functions in executing body activities [10, 11]. In this intriguing reciprocal connection, underlying emotional processing in the brain transmits to bodily changes associated with emotion-specific expression, cognition, and motivated behavior to even assimilate the conscious experience of being fearful.

\section{Emotion processing brain circuitry}

Interacting areas of the brain are structurally interrelated, enabling flexible coherent functioning, such as the limbic system $[12,13]$. The system is conceived as an essential component of the emotional brain where interacting subcortical structures meet the cerebral cortex [14, 15]. The amygdala located near the hippocampus, interconnecting with other components of the limbic system, is responsible for many aspects of emotions, including recognition of facial expression of fear and anxiety-related memories $[16,17,18]$. Alternatively, the amygdala may register emotional stimuli and initiate coordinated physiological and behavioral responses that underlie defensive reactions [19, 20]. Some studies have shown, using functional magnetic resonance imaging (fMRI), that these brain regions where the amygdala as being directly responsible for immediate reaction associated with conditioned fear, become active when experiencing anxiety $[21,22]$ which generally helped to shed light on the underlying neurobiological causes of 
anxiety $[23,24]$. The limbic system attends a variety of functions. In addition to its involvement in metabolism, it controls the physical and psychological responses to environmental stimuli, especially those with emotional content $[25,26]$. Together with the hypothalamus, the amygdala produces autonomic components of feelings and is responsible for mediating all emotional responses and influence homeostatic mechanisms and neuroendocrine signalling [27].

Conversely, the close association between the amygdala and hippocampus provides complimentary action on emotionally salient stimuli and sub-optimal stress-related information, which generates responses through the hypothalamic-pituitary-adrenal (HPA) and other effectors systems [28] (Fig. 1). In several imaging studies, the amygdala is found to mediate emotional reactions that modulate fear and anxiety behavior [29, 30, 31]. With its role as an integrative detective center for emotion, the hippocampus likewise plays an essential role in the formation of new memories and expression of adaptive emotional behaviors. The critical function of fear and anxiety acts as a signal of threat or motivational conflict, and thus triggers appropriate adaptive responses. Craig and colleagues (1995) underscored that anxiety is a generalized response to an unknown threat or internal conflict.

In contrast, fear is focused on known external danger, which implies a different mechanism of the neural circuit [32]. This response is likely to be mediated by a network of subcortical structures centered on the amygdala. To reiterate, the amygdala contributes to emotional arousal processing and is specifically involved in memory processes and motivation. Consistent with this view, some ablation and fear extinction studies showed that the amygdala is directly responsible for responding to threats that contribute to feelings of anxiety [12, 33, 34]. By the same intention, they found that patients with diminished feelings following amygdala damage may reflect the elimination of the indirect consequences of amygdala activity on feelings without increasing their negative impact $[35,36]$. Another comparable investigation of Feinstein et al. (2013) inferred that a healthy amygdala might well usually serve to inhibit panic. In another empirical observation suggested that hyperactive amygdala can result in dramatic changes in emotional responses such as fear and anxiety responses [37]. These findings presumably indicate enormous evidence that the amygdala plays an essential role in processing emotions and anxiety states. However, some studies indicated that patients with amygdala damage can still feel fear, panic, and express pain $[38,39]$. From the perspective of this empirical result, numerous experimental paradigms put forward the process by which the subjects modify the expression, the experience, and the physiology of their emotions, as a form of cognitive change characterized by adjusting the meaning of an emotional stimulus [40, 41, 42]. According to these experimental studies, which endeavored to apply emotion regulation strategies have made explicit that subjects can modify the behavioral expression, experience, and the bodily processes of their emotions [43, 44, 45].

In another study, LeDoux (2015) stressed, the amygdala is an essential part of the circuit that allows the brain to detect and respond to threats, but it is not necessary to feel fear. He added that once learned, the emotional and behavioral response occurs unconsciously and automatically. Indeed, embedded within this experience shifts, the emotional value of a stimulus is modified. The subject is expected to more automatic responses to match the newly acquired stimulus value [46, 47]. In this view, physiological, cognitive, and behavioral responses may simultaneously form the experience of emotion [48]. Specific limbic system structures, the hypothalamus, amygdala, and the hippocampus, deals with the basic drives, emotions, motivations, and memory that can have a substantial influence on the cognitive process $[1,49]$. These regions work in concert to both generate and modulate fear responses to imminent and identifiable threats [50,51], where the amygdala and the hippocampus carry out synergistically to form long-term memories of significant emotional events.

There are many processes associated with the limbic system. Still, the system is most frequently linked to emotion, and affective reactivity believed to involve such cognitive processes which in turn has to do with the role of a conscious effort to control innate behavior thought and feeling $[1,52,53]$. The essence of this point, suggests anxiety response starts in a region of the brain called the amygdala [54] and dorsal anterior cingulate cortex (dACC) process aversive signals and send output to the hypothalamus, basal ganglia, and brainstem to produce defensive behaviors [35, 55]. Supplementary to this study are the inquiries making impressive claims that, although it is held that the limbic system and in particular the amygdala because they have been identified with the highest density of neuropeptides that influence the activity of the brain and the body in specific manners [4, 7, 56, 57]. The investigation addressed that this mixture of neurotransmitters called neuropeptides travels throughout the body and the brain to support the experience of emotion through body-brain interactions $[58,59]$. Neuropeptides presumably enhance the perception of multisensory signals, and in the case of threats, the signals are suggested to reach a threshold that triggers a fear response.

\section{Anxiety-related neuro-circuitry and the hypothalamic-pituitary-adrenal axis}

In an intriguing amygdala's reciprocal connections with many brain regions are found to display high levels of neural activity involved in emotion generating actions that may initiate critical physiological and behavioral responses across the anxiety spectrum [35] (Fig. 1). It responds to a variety of emotional stimuli and interacts with emotional memory, mental state as well as focuses on automatic responses such as threat detection [6,27]. Due to strong emotional content involved, fear is a triggered response and is linked with the functioning of the amygdala [60]. In the absence of the amygdala, the alarm in our brain that pushes us to avoid danger is missing [36]. The brain is the crucial organ of anxiety response because it determines what is potentially threatening, and therefore stressful [61]. It also regulates the behavioral and physiological responses to potentially stressful experiences. It determines how one should respond emotionally by using input from the subject's stored knowledge. The hippocampus and the amygdala regulate the HPA axis, which mediates the fight or flight response [8]. Like the rest of the brain, the hypothalamus communicates with the rest of the body through the nervous system to shift the body's energy resources towards fight or flight [62]. Tension triggers the HPA axis, a neuroendocrine system that regulates central and peripheral homeostatic adaptive responses to 


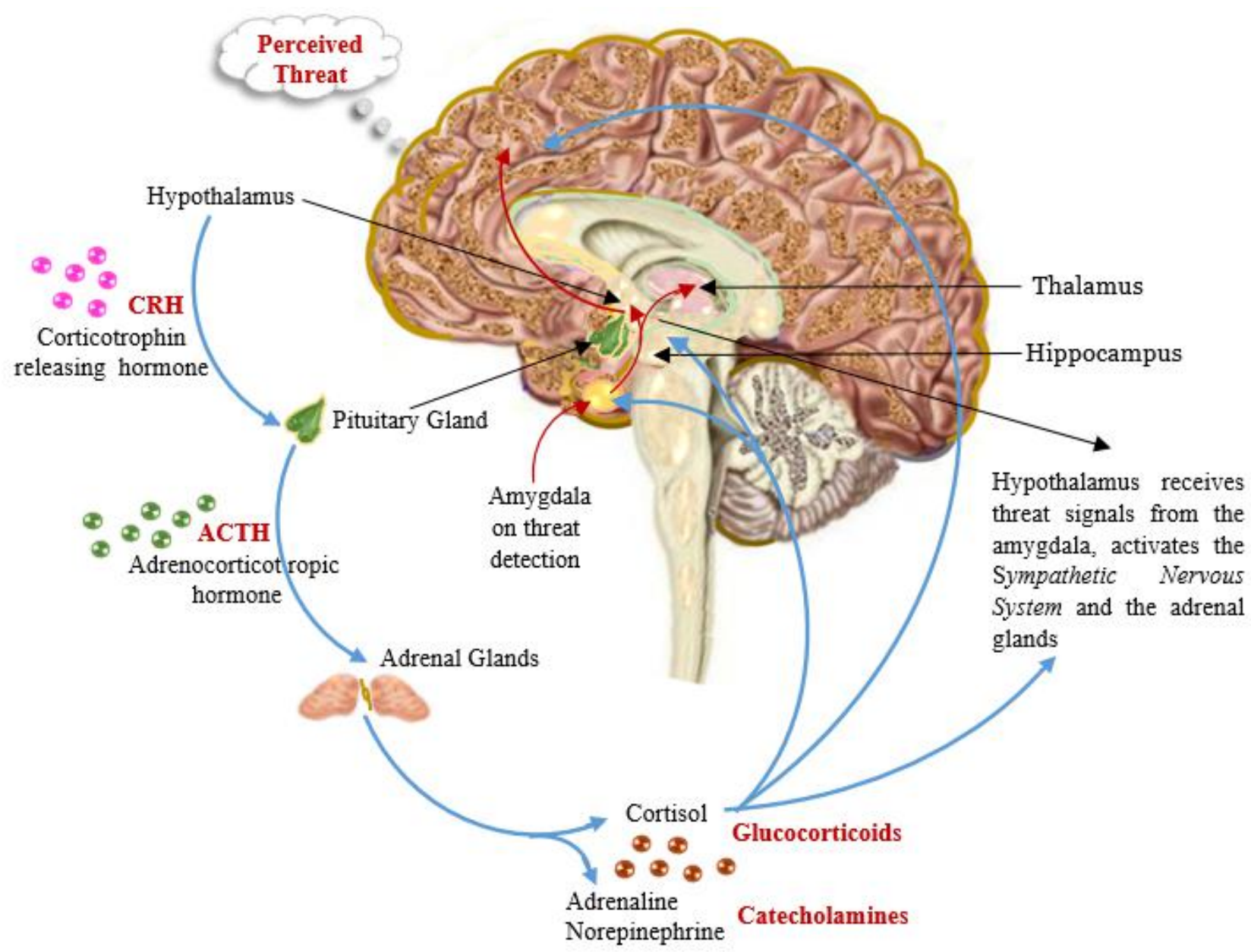

Fig. 1. A schematic illustration of the brain's complex circuitry mediating fear responses and anxiety behavior along with hormonal mechanisms responsible for hyperactivity of the HPA axis in response to a threat. When the brain receives a threat signal, the hypothalamus which is activated by the amygdala triggers the release of $\mathrm{CRH}$. It funnels $\mathrm{CRH}$ to activate the Pituitary gland, which ultimately controls the other endocrine glands and body's hormonal response to stress. This occurs via the action of CRH that stimulates the pituitary synthesis of ACTH as an interconnecting element of the HPA Axis. In turn, ACTH travels down the bloodstream and stimulates the adrenal glands located atop of both kidneys to secrete more stress and threat hormones including Cortisol, Adrenaline, and Noradrenaline and release them into the bloodstream to assist the body in handling threat or stress better resulting in higher levels of cortisol in the blood. However, prolonged high cortisol levels in the bloodstream exacerbate anxiety and interfere with the body's natural self-repair mechanism. Hence, Cortisol's far-reaching, systemic effects play numerous roles in the body's effort to carry out its processes and maintain homeostasis. Correspondingly, these are the hormones, particularly cortisol, involved in the regulation of the HPA system that plays a vital role in anxiety-related disorders.

anxiety [63, 64]. The HPA axis regulates various bodily processes and is a vital component of the body's neuroendocrine response and behavioral changes in mediating fear and anxiety [65].

When a threat is perceived, the body reacts by secreting stress hormones into the bloodstream. These are complex chemicals that convey messages throughout the body via the bloodstream and trigger specific anxiety responses (Fig. 1). The hypothalamus triggers the pituitary gland, which causes secretion and synthesis of another hormone called corticotrophin-releasing hormone (CRH) that enables the body to continue to resist the stress or threat until homeostasis is resumed [66, 50]. As outlined in Fig. 1, the CRH circuit stimulates the pituitary gland to secrete adrenocorticotropic hormone (ACTH) into the bloodstream. The anterior pituitary gland controls the secretion of ACTH in response to CRH from the hypothalamus. The adrenal gland receptors detect the high levels of ACTH, which also stimulate the secretion of cortisol. Often called the stress hormone, cortisol regulates energycontrolling blood sugar levels, mobilizes energy to target tissues and muscles, and reduces inflammation in the body. Cortisol concentration plays a vital role in the body's stress response as an indicator of stress level [67]. However, when cortisol levels rise, the HPA axis starts to slow down the release of CRH from the hypothalamus and ACTH from the pituitary gland, as demonstrated in Fig. 1. As an adaptive response to a threat, the level of various hormones also changes. When threat or stress goes high, so does cortisol level [68, 69].

Correspondingly, ACTH levels start to fall when cortisol is high. As detailed in Fig. 1, the end-product of the HPA axis is cortisol and other stress hormones norepinephrine and epinephrine, which contribute to the inflammatory response. Cortisol, an es- 
sential glucocorticoid, has many significant functions in the natural processes of the body, involved in regulating metabolism, immune response, and general homeostasis [70]. Cortisol potentiates the body into a general state of arousal, giving that hyperactive and overwhelming influences on the affect [71]. To foster physiological response, cortisol tapped into proteins stored in the liver, provides the body with high amounts of glucose in the bloodstream, enhances brain's use of glucose and increases the availability of substances that repair tissues, therefore, reducing inflammation $[61,72,73]$.

\section{The amygdala's molecular mechanism un- derlying anxiety}

The CNS coordinates all functions of the body systems, organs, down to the primary functional unit - the neuron. Every behavior, emotions, and the essential features of living interact in essential ways in the entire brain. How neurons behave concerning emotions ultimately implicates for a central state of emotion, like fear and anxiety. The HPA axis integrates the neuroendocrine functions as well as regulates hormonal and neurotransmitter release, particularly the $\gamma$-aminobutyric acid (GABA) neurotransmitter systems innervating stress and anxiety-associated brain [74, 75, 76]. Conventional neurotransmitters can either be inhibitory or excitatory that are released by presynaptic axon terminal into the synapse upon stimulation of specific receptors. The chief inhibitory neurotransmitter is GABA, whereas glutamate is the main excitatory neurotransmitter in the CNS [77, 78]. GABA, an amino acid produced naturally in the brain functions as the principal inhibitory neurotransmitter because it inhibits specific brain signals and slows down the flow of information, thus reduces the activity of the nervous system $[78,79]$. When one is anxious, overreactive fear circuits are coursing from the lateral and central nucleus of the amygdala.

Moderating the extent to which the GABA neurotransmitters connected to the central nucleus of the amygdala are hence adequately positioned via synapses, encourage synaptic inhibition [80]. As outlined in Fig. 2, these synapses are tiny gaps filled with ions where communication takes place between neurons (axon and dendrites) via neurotransmitters. These neurotransmitters are molecules that travel from one neuron to another neuron to allow chemical transmission. They cross a synapse between them to communicate with each other, as shown in Fig. 2. Upon activation, the messages they send are believed to play a role in anxiety regulation. GABA and its receptor activation can cause a massive increase in chloride conductance through the cell membrane [81]. This facilitates a regulatory role in maintaining a balance between neuronal excitation and inhibition. When GABA molecules are released into the synaptic cleft, they bind to their receptors. The latter receptors function to inhibit or reduce the neuronal activity of the neurons by inhibiting nerve transmission, thereby reducing unwanted brain excitability. This ultimately produces a calming effect and helps to bring balance to the body and maintains homeostatic adaptive responses to anxiety [79]. A synapse is a site of functional contact between neurons that facilitate the transmission of impulses from one (presynaptic) neuron to another (postsynaptic) neuron. Typically, when GABA binds to its target protein receptors - known as $\mathrm{GABA}_{A}$ receptors and opens up the chloride ion channels, it causes depolarization and thus decreases cellular excitability by inhibiting nerve transmission. However, GABA is not the only molecule that can change this channel receptor's opening. The mechanism underlying this effect involves blocking specific brain signals to reduce hyperactivity of the amygdala and thereby prevent generating inappropriate emotional and anxious responses [82]. Current studies claim that when the GABA neurotransmitter is released it reduces anxiety. It is its natural function to reduce the activity of the neurons to which it binds. Some studies suggest that endogenous GABA helps to control fear and anxiety when neurons become overexcited. GABA plays a vital role in behavior and cognition, and its inhibitory interneurons represent a promising therapeutic target for the treatment of anxiety disorders.

\section{Hypothalamic-Pituitary-Adrenal distur- bances associated with anxiety disorders}

Being highly involved in the emotional reactions when danger is perceived, the amygdala sends a distress signal to the hypothalamus which stimulates the sympathetic nervous system and triggers a cascade of hormones resulting in the final release of cortisol from the adrenal cortex situated atop the kidney [25, 83, 84]. Risks seem to be linked to the HPA axis releasing stress hormones abnormally [85], it not only causes anxiety and depression, but also affects the digestion, immune system, mood and emotions, sexuality, and energy storage and use, because the HPA axis involves these complex range of functions. Most body cells have cortisol receptors that elicit effects on many tissues under physiological conditions [86] (Fig. 1). In this regard, the manifestation of the HPA axis that transects with those of both anxiety dysfunction, is caused by tension and anxiety. Healthy body functioning can be disrupted when cortisol is released in excess due to prolonged activation of stress response systems in the body and brain. Thus, when a level of cortisol interacts with the hypothalamus, the HPA axis will slow down its activity to maintain hormonal balance within appropriate levels. In the presence of circulating hormonal factors, cortisol and other stress hormones via the bloodstream towards relevant organs, mobilize the body's resources by increasing energy and decreasing inflammation, especially upon injuries. These systems-level physiological changes suggest that CRF plays an important role both in the development of a functional HPA axis and is a major integrator of adaptive responses in mediating anxiety-related behavioral consequences [87, 88]. However, the high levels of cortisol due to unrelenting anxiety can wear down the brain's ability to function appropriately, including metabolism. Cortisol has been considered one of the main culprits in the stressanxiety connection, although it plays a fundamental role in helping one cope with threats [54]. It can be enlightening to consider that anxiety disorders involve prominent disturbances of both cognitive and emotional regions deeply interwoven in the fabric of the brain that can be conceptualized as disorders of the emotionalcognitive brain [51, 52, 89]. Disturbances in how fear-inducing information is perceived and processed surges a defective pattern of thinking and leading to different psychological vulnerabilities and the emotional risks that go with it $[12,90,91]$. Anxiety is a subjective experience of discomfort in response to an actual or perceived threat via projections to the hypothalamus, visual cortex, 


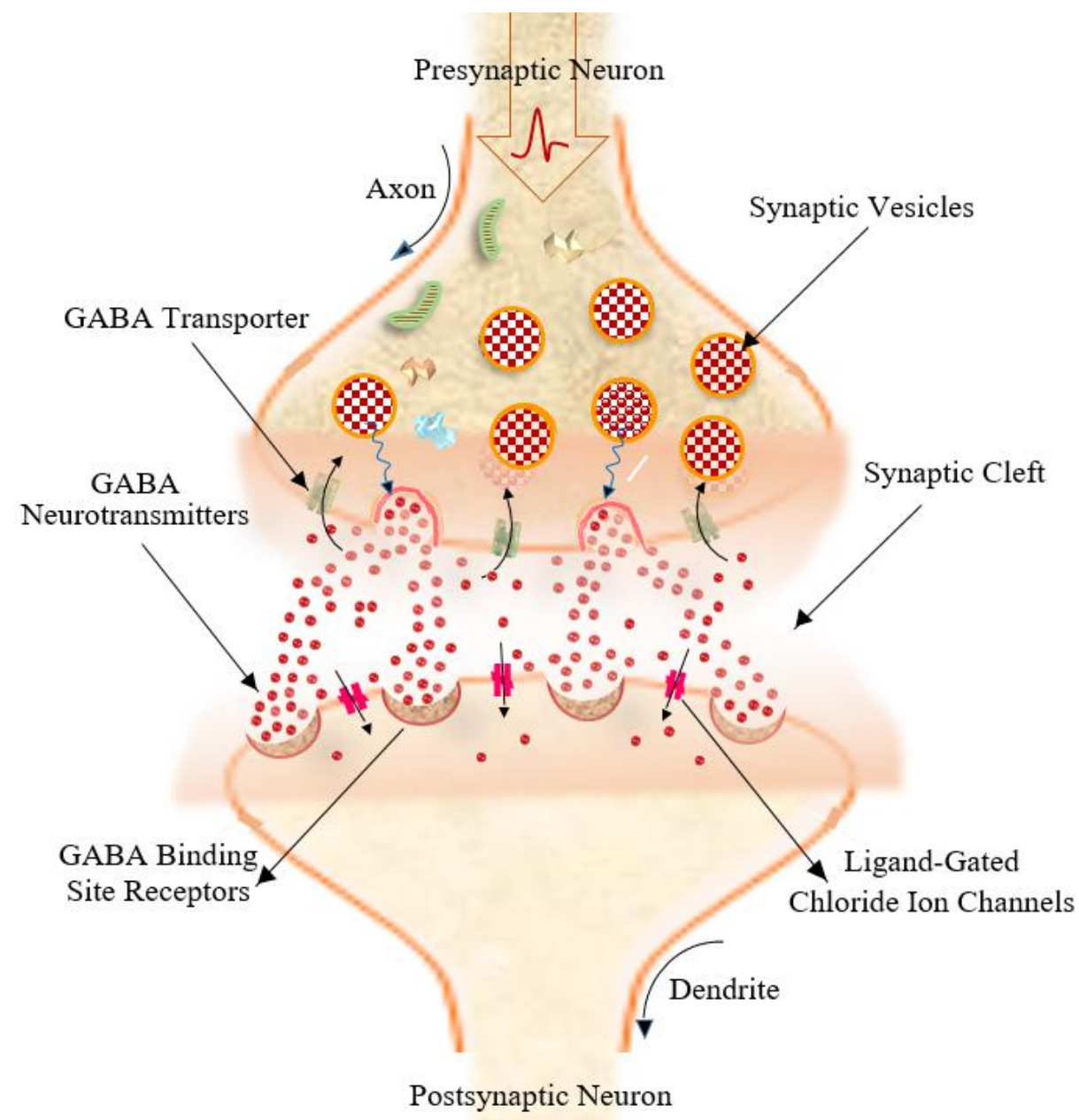

Fig. 2. Illustration depicting the brain circuits in the amygdala to include an inhibitory network of GABA interneurons to transmit neural information across the synapse. GABA has a structure of an amino acid. Neurotransmitters stored in synaptic vesicles that are positioned along the presynaptic membrane enhance molecular secretion to modulate anxiety responses. When a neural message reaches the axon terminal, the GABA neurotransmitter is released, carrying information across the synaptic gap to the receiving neuron (dendrite). GABA plays a vital role in reducing overwhelming feelings of anxiety by slowing down the signals or neuronal excitability throughout the nervous system.

and prefrontal cortex [92]. The perception of the threat depends upon the anxious, as one perceives threats about self, the world, or related to the future. This threat perception elicits a physiologic reaction associated with rapid heartbeat, blood pressure, sweating, and an overall sense of vigilance, exacerbating the activation of the primal response of flight or fight [93, 94]. In some cases, anxiety symptoms may persist even after the threat is gone. Yet, alterations in the HPA axis suggest the neurobiological basis of anxiety disorders with reported structural and functional differences that can manifest dispositional negativity across disparate psychopathologies [95].

Anxiety is not the same as fear, which is a response to a real or immediate threat and anxiety [96, 97]. Anxiety involves the expectation of future threats, is fear-based, and may occur unexpectedly, even in the absence of real danger. Craske and Stein (2016) indicated that those with heightened sensitivity to anxiety respond to those sensations with dread and pressing urge to escape a dangerous situation. Hence, anxiety can only be understood by taking into account some of its cognitive traits because a primary aspect of anxiety appears to be uncertainty, which is a negative effect on self-esteem leading to insecurity [98]. Thus, anxiety and insecurity are both fears for abstract threats that impede the ability to mitigate its adverse impact resulting in helplessness and isolation [99]. A moderate amount of anxiety helps subjects think and act more effectively and is a normal emotion under stressful circumstances of threat. Thus, mild anxiety is adaptive and sustains motivation for survival. It is characterized by adaptive emotion that prepares one both physically and psychologically for coping with an adverse event that could be dangerous [100]. Although adaptation is not easy, there have to be conscious efforts in part of the executive control system necessary to bring the body and mind in tune and coherence about executing a behaviour-the anxious feel vulnerable and weak between threat perceptions. Thus, the anxious often feels a sense of uncertainty and helplessness, becoming withdrawn with a distinct need for solitude [93, 101]. It is important to note that the entire process begins with negative thoughts due to stressful events and constant threats such as the COVID-19 pandemic that intensified over an extended pe- 
riod, escalating through, until panic attacks set in [102]. Intrusive thoughts build-up recurring concerns of risky situations involving threats and bring about the onset of anxiety and panic disorder. Symptoms are caused by feelings of extreme apprehension of impending doom that occur even in the absence of actual danger.

Adapting to anxiety involves physiological and psychological response stressing the destructive and stressful impact on what might happen in the future, such as the current COVID-19 pandemic. Thus, it is always future-oriented, fear-based, and focused on worrying over what is about to come, and conceivably one may become excessively anxious about the need for reasonable safety precautions [93, 103, 104]. Therefore, this leads to the thinking part of anxiety, which brings dominant symptoms of worry, which suggests always planning, looking ahead, trying to control circumstances, and a stressful urge to defeat a threat $[105,106]$. In other words, anxiety is only a problem when it extends beyond legitimate worry in an unreasonable and disproportionate to the actual threat. Indeed, entrenched within a diffuse apprehension that is vague is associated with feelings of uncertainty and helplessness.

\section{Conclusion}

Increasing brain activity studies have made significant contributions to our understanding of the brain responsiveness to emotional perception in addition to biological processes through its mediation of fear and anxiety-related behavior. We gave much attention to mapping output hormonal pathways to identify a specific brain circuitry for the functional roles played by various brain regions and their mutual interactions, especially those that trigger an emotional response. The period when the brain, mind, and emotion are in synch highlights the connection between cognitive and emotional functioning. In a related manner, peripheral physiological changes can all go along with various emotional experiences that would support defensive psychophysiological adjustments. These representations reflect more closely to approximate parallel brain regions, and neural events are thought to be most directly involved in the development of cognitive-behavioral response. Accordingly, we refer to brain circuits that detect and respond to threats as physiologically self-protective functions, towards behavioral expressions in avoiding threats as defensive behaviors. Amygdala activation indicates a close interaction with the cortical brain region serves a pivotal role in cognitive and emotional functions, which dynamically influence the mental state.

To assess these essential considerations, this review has focused on understanding how the HPA stress and anxiety-response pathway, and the amygdala activation contribute to the circuitry underlying adaptive or defensive and pathological anxiety behaviors. Converging evidence provides significant insights that, although the emotional centers can appear to be out of control, perhaps especially when it continually senses threat signals, which could account that amygdala damage can result in. Correspondingly, the cortex has a mechanism in emotion processing, that filters out and controls the emotional input the cortex is receiving from the amygdala. This is expected because the amygdala serves as the interface between emotion and cognition, and with the help of the HPA axis, the amygdala, and the prefrontal cortex, modulate adaptive success. In this respect, much remains to be discovered to elucidate whether the neurochemical mechanism involved in GABA molecules in brain circuits relevant to anxiety processes, could provide valuable information regarding the psychobiology of anxiety and its reducing effects. Beyond question, it is entirely rational to be anxious. Taking specific action to control and focus on physiological responses underlying hormonal and molecular mechanisms that drive behavioral adaptation and resilience, help maintain a sense of normalcy. In the final analysis, neuroscience has much to offer to the psychology of human behavior, feelings, and both conscious and unconscious thoughts. Still, like any new approach, these contributions will take time to realize. Future work in this emerging field should focus on the intersection of biological and psychological theories and cognitive neuroscience.

\section{Acknowledgments}

We thank two anonymous reviewers for improving the quality of the paper. I-Code, Universiti Sultan Zainal Abidin, supported this research.

\section{Conflict of Interest}

Authors declare that the research was conducted without any conflict of interest.

Submitted: July 28, 2020

Accepted: September 18, 2020

Published: September 20, 2020

\section{References}

[1] Harlé KM, Shenoy P, Paulus MP. The influence of emotions on cognitive control: feelings and beliefs-where do they meet? Front Hum Neurosci. 2013; 7: 508.

[2] Almada LF, Pereira A Jr, Carrara-Augustenborg C. What affective neuroscience means for science of consciousness. Mens Sana Monogr. 2013; 11(1): 253-273.

[3] Edelman GM, Gally JA, Baars BJ. Biology of consciousness. Front Psychol. 2011; 2: 4.

[4] Pape HC, Pare D. Plastic synaptic networks of the amygdala for the acquisition, expression, and extinction of conditioned fear. Physiol Rev. 2010; 90(2): 419-463.

[5] Davidson RJ. Darwin and the neural bases of emotion and affective style. Ann N Y Acad Sci. 2003; 1000: 316-336.

[6] Damasio AR, Grabowski TJ, Bechara A, et al. Subcortical and cortical brain activity during the feeling of self-generated emotions. Nat Neurosci. 2000; 3(10): 1049-1056.

[7] Panksepp J (1998) Affective Neuroscience: The Foundations of Human and Animal Emotions. New York, Oxford University Press.

[8] Heim C, Newport DJ, Mletzjo T, Miller AH, Nemeroff CB. The link between childhood trauma and depression: Insights from HPA axis studies in humans. Psychoneuroendocrinology. 2008; 33(6): 693710 .

[9] Tononi G. Consciousness, information integration, and the brain. Prog Brain Res. 2005; 150: 109-126.

[10] Pessoa L, Padmala S, Kenzer A, Bauer A. Interactions between cognition and emotion during response inhibition. Emotion. 2012; 12(1): 192-197.

[11] Cacha LA, Poznanski RR. Associable representations as field of influence for dynamic cognitive processes. J Integr Neurosci. 2011; 10(4): 423-437.

[12] LeDoux JE. Emotion circuits in the brain. Annu Rev Neurosci. 2000; 23: $155-184$.

[13] Nieuwenhuys R, Voogd J, van Huijzen C (1996). The Human Central Nervous System. Berlin, Springer.

[14] Dalgleish T. The emotional brain. Nat Rev Neurosci. 2004; 5(7): 583589. 
[15] Ellsworth PC. William James and emotion: is a century of fame worth a century of misunderstanding? Psychol Rev. 1994; 101(2): 222-229.

[16] Hennion S, Szurhaj W, Duhamel A, Lopes R, Tyvaert L, Derambure $\mathrm{P}$, et al. Characterization and prediction of the recognition of emotional faces and emotional bursts in temporal lobe epilepsy. J Clin Exp Neuropsychol. 2015; 37(9): 931-945.

[17] Monti G, Meletti S. Emotion recognition in temporal lobe epilepsy: A systematic review. Neurosci Biobehav Rev. 2015; 55: 280-293.

[18] Richter-Levin G, Akirav I. Amygdala-hippocampus dynamic interaction in relation to memory. Mol Neurobiol. 2000; 22(1-3): 11-20.

[19] Salzman CD and Fusi S. Annual Review of Neuroscience. 2010; 33(1): 173-202.

[20] Delgado MR, Nearing KI, Ledoux JE, Phelps EA. Neural circuitry underlying the regulation of conditioned fear and its relation to extinction. Neuron. 2008; 59(5): 829-838.

[21] Damsa C, Kosel M, Moussally J. Current status of brain imaging in anxiety disorders. Curr Opin Psychiatry. 2009; 22(1): 96-110.

[22] Kim JE, Dager SR, Lyoo IK. The role of the amygdala in the pathophysiology of panic disorder: evidence from neuroimaging studies. Biol Mood Anxiety Disord. 2012; 2: 20.

[23] Del Casale A, Serata D, Rapinesi C, Kotzalidis GD, Angeletti G, Tatarelli R, Ferracuti S, et al. Structural neuroimaging in patients with panic disorder: findings and limitations of recent studies. Psychiatr Danub. 2013; 25(2): 108-114.

[24] Paulus MP. The role of neuroimaging for the diagnosis and treatment of anxiety disorders. Depress Anxiety. 2008; 25(4): 348-356.

[25] Hakamata Y, Komi S, Moriguchi Y, Izawa S, Motomura Y, Sato E, et al. Amygdala-centred functional connectivity affects daily cortisol concentrations: a putative link with anxiety. Sci Rep. 2017; 7(1): 8313.

[26] Bota M, Sporns O, Swanson LW. Architecture of the cerebral cortical association connectome underlying cognition. Proc Natl Acad Sci U $S$ A. 2015; 112(16): E2093-E2101.

[27] Tovote P, Fadok JP, Lüthi A. Neuronal circuits for fear and anxiety. Nat Rev Neurosci. 2015; 16(6): 317-331.

[28] Lebow MA, Chen A. Overshadowed by the amygdala: the bed nucleus of the stria terminalis emerges as key to psychiatric disorders. Mol Psychiatry. 2016; 21(4): 450-463.

[29] LaBar KS, Gatenby JC, Gore JC, LeDoux JE, Phelps EA. Human amygdala activation during conditioned fear acquisition and extinction: a mixed-trial fMRI study. Neuron. 1998; 20(5): 937-945.

[30] Whalen PJ, Shin LM, McInerney SC, Fischer H, Wright CI, Rauch SL. A functional MRI study of human amygdala responses to facial expressions of fear versus anger. Emotion. 2001; 1(1): 70-83.

[31] Sah P, Faber E S L, Lopez De Armentia M, Power J. The amygdaloid complex: anatomy and physiology. Physiol Rev. 2003; 83(3): 803834

[32] Mobbs D, Hagan CC, Dalgleish T, Silston B, Prévost C. The ecology of human fear: survival optimization and the nervous system. Front Neurosci. 2015; 9: 55.

[33] Davis M, Whalen PJ. The amygdala: vigilance and emotion. Mol Psychiatry. 2001; 6(1): 13-34.

[34] Davis M, Shi C. The extended amygdala: are the central nucleus of the amygdala and the bed nucleus of the stria terminalis differentially involved in fear versus anxiety? Ann N Y Acad Sci. 1999; 877: 281291.

[35] Buckholtz JW, Meyer-Lindenberg A. Psychopathology and the human connectome: toward a transdiagnostic model of risk for mental illness. Neuron. 2012; 74(6): 990-1004.

[36] Feinstein JS, Adolphs R, Damasio A, Tranel D. The human amygdala and the induction and experience of fear. Curr Biol. 2011; 21(1): 3438.

[37] Kim JE, Dager SR, Lyoo IK. The role of the amygdala in the pathophysiology of panic disorder: evidence from neuroimaging studies. Biol Mood Anxiety Disord. 2012; 2: 20.

[38] Anderson AK, Phelps EA. Is the human amygdala critical for the subjective experience of emotion? Evidence of intact dispositional affect in patients with amygdala lesions. J Cogn Neurosci. 2002; 14(5):
709-720.

[39] Feinstein JS, Khalsa SS, Salomons TV, Prkachin KM, Frey-Law LA, Lee JE, et al. Preserved emotional awareness of pain in a patient with extensive bilateral damage to the insula, anterior cingulate, and amygdala. Brain Struct Funct. 2016; 221(3): 1499-1511.

[40] Shin LM, Wright CI, Cannistraro PA, Wedig MM, McMullin K, Martis, B, et al. A functional magnetic resonance imaging study of amygdala and medial prefrontal cortex responses to overtly presented fearful faces in posttraumatic stress disorder. Arch Gen Psychiatry. 2005; 62(3): 273-281.

[41] Etkin A, Klemenhagen KC, Dudman JT, Rogan MT, Hen R, Kandel $\mathrm{ER}$, et al. Individual differences in trait anxiety predict the response of the basolateral amygdala to unconsciously processed fearful faces. Neuron. 2004; 44(6): 1043-1055.

[42] Gross JJ. Antecedent- and response-focused emotion regulation: divergent consequences for experience, expression, and physiology. $J$ Pers Soc Psychol. 1998; 74(1): 224-237.

[43] Blalock DV, Kashdan TB, Farmer AS. Trait and Daily Emotion Regulation in Social Anxiety Disorder. Cogn Ther Res 2016; 40: 416425 .

[44] Sheppes G, Scheibe S, Suri G, Radu P, Blechert J, Gross JJ. Emotion regulation choice: a conceptual framework and supporting evidence. J Exp Psychol Gen. 2014; 143(1): 163-181.

[45] Gross JJ, Richards JM, John OP (2006). Emotion Regulation in Everyday Life. In Snyder DK, Simpson J, Hughes JN (Eds.), Emotion regulation in couples and families: Pathways to dysfunction and health (pp. 13-35). American Psychological Association. https: //doi.org/10.1037/11468-001.

[46] Kehagia AA, Murray GK, Robbins TW. Learning and cognitive flexibility: frontostriatal function and monoaminergic modulation. Curr Opin Neurobiol. 2010; 20(2): 199-204.

[47] Broomfield NM, Turpin G. Covert and overt attention in trait anxiety: a cognitive psychophysiological analysis. Biological Psychology. 2005; 68(3): 179-200.

[48] Kassam KS, Mendes WB. The effects of measuring emotion: physiological reactions to emotional situations depend on whether someone is asking. PLoS One. 2013; 8(7): e64959.

[49] Proudfit GH, Inzlicht M, Mennin DS. Anxiety and error monitoring: the importance of motivation and emotion. Front Hum Neurosci. 2013; 7: 636 .

[50] Shin, L., Liberzon, I. The Neurocircuitry of Fear, Stress, and Anxiety Disorders. Neuropsychopharmacol 2010; 35: 169-191.

[51] Panksepp J. Affective consciousness: Core emotional feelings in animals and humans. Conscious Cogn. 2005; 14(1): 30-80.

[52] Ochsner KN, Gross JJ. The cognitive control of emotion. Trends Cogn Sci. 2005; 9(5): 242-249.

[53] Proverbio AM, Riva F, Paganelli L, Cappa SF, Canessa N, Perani D, et al. Neural coding of cooperative vs. affective human interactions: $150 \mathrm{~ms}$ to code the action's purpose. PLoS One. 2011; 6(7): e22026.

[54] Stein MB, Simmons AN, Feinstein JS, Paulus MP. Increased amygdala and insula activation during emotion processing in anxietyprone subjects. Am J Psychiatry. 2007; 164(2): 318-327.

[55] Lee S, Kim SJ, Kwon OB, Lee JH, Kim JH. Inhibitory networks of the amygdala for emotional memory. Front Neural Circuits. 2013; 7: 129

[56] Dong HW, Petrovich GD, Swanson LW. Topography of projections from amygdala to bed nuclei of the stria terminalis. Brain Res Brain Res Rev. 2001; 38(1-2): 192-246.

[57] Pert CB (1999). Molecules of Emotion: The Science Behind MindBody, 1st ed. New York: Simon \& Schuster, 368pp.

[58] Fuxe K, Li XM, Bjelke B, Hedlund PB, Biagini G, Agnati LF. Possible mechanisms for the powerful actions of neuropeptides. Ann $N$ Y Acad Sci. 1994; 739: 42-59.

[59] Ludwig M, Leng G. Dendritic peptide release and peptide-dependent behaviours. Nat Rev Neurosci. 2006; 7(2): 126-136.

[60] Van den Stock J, Tamietto M, Sorger B, Pichon S, Grézes J, de Gelder B. Cortico-subcortical visual, somatosensory, and motor activations for perceiving dynamic whole-body emotional expressions with and without striate cortex (V1). Proc Natl Acad Sci US A. 2011; 108(39): 
16188-16193.

[61] McEwen BS. Physiology and neurobiology of stress and adaptation: central role of the brain. Physiol Rev. 2007; 87(3): 873-904.

[62] Jansen AS, Nguyen XV, Karpitskiy V, Mettenleiter TC, Loewy AD. Central command neurons of the sympathetic nervous system: basis of the fight-or-flight response. Science. 1995; 270(5236): 644-646.

[63] Freberg LA (2015) Discovering Behavioral Neuroscience: An Introduction to Biological Psychology. Boston, Cengage Learning.

[64] Bale TL, Vale WW. CRF and CRF receptors: role in stress responsivity and other behaviors. Annu Rev Pharmacol Toxicol. 2004; 44: 525-557.

[65] Gray TS, Bingaman EW. The amygdala: corticotropin-releasing factor, steroids, and stress. Crit Rev Neurobiol. 1996; 10(2): 155-168.

[66] Aguilera G. HPA axis responsiveness to stress: Implications for healthy aging. Exp Gerontol. 2011; 46(2-3):90-95.

[67] Cook CJ. Glucocorticoid feedback increases the sensitivity of the limbic system to stress. Physiol Behav. 2002; 75(4): 455-464.

[68] Ebrecht M, Hextall J, Kirtley LG, Taylor A, Dyson M, Weinman J. Perceived stress and cortisol levels predict speed of wound healing in healthy male adults. Psychoneuroendocrinology. 2004; 29(6): 798809.

[69] Mavoungou E, Bouyou-Akotet MK, Kremsner PG. Effects of prolactin and cortisol on natural killer (NK) cell surface expression and function of human natural cytotoxicity receptors (NKp46, NKp44 and NKp30). Clinical \& Experimental Immunology. 2005, 139(2): 287-96.

[70] Peters A, McEwen BS, Friston K. Uncertainty and stress: Why it causes diseases and how it is mastered by the brain. Prog Neurobiol. 2017; 156: 164-188.

[71] Biagini G, Pich EM, Carani C, Marrama P, Agnati LF. Postnatal maternal separation during the stress hyporesponsive period enhances the adrenocortical response to novelty in adult rats by affecting feedback regulation in the CA1 hippocampal field. Int J Dev Neurosci. 1998; 16(3-4): 187-197.

[72] Otmishi P, Gordon J, El-Oshar S, Li H, Juan G, Mereddef S, et al. Neuroimmune interaction in inflammatory diseases. Clin Med Circ Respirat Pulm Med. 2008; 2: 35-44.

[73] Gunnar M, Quevedo K. The neurobiology of stress and development. Annu Rev Psychol. 2007; 58: 145-173.

[74] Crestani F, Lorez M, Baer K, Benke D, Laurent JP, Belzung C, et al. Decreased GABAA-receptor clustering results in enhanced anxiety and a bias for threat cues. Nat Neurosci. 1999; 2(9): 833-839.

[75] Bowery NG (2010) GABABReceptor Pharmacology. In Blackburn TP(Ed.) Advances in Pharmacology (pp. 1-483). Elsevier.

[76] Romanov RA, Alpár A, Hökfelt T, Harkany T. Molecular diversity of corticotropin-releasing hormone mRNA-containing neurons in the hypothalamus. J Endocrinol. 2017; 232(3): R161-R172.

[77] Bloom FE, Iversen LL. Localizing 3H-GABA in nerve terminals of rat cerebral cortex by electron microscopic autoradiography. Nature. 1971; 229(5287): 628-630.

[78] Compagnone NA, Mellon SH. Neurosteroids: biosynthesis and function of these novel neuromodulators. Front Neuroendocrinol. 2000; 21(1): 1-56.

[79] Sanders SK, Shekhar A. Regulation of anxiety by GABAA receptors in the rat amygdala. Pharmacol Biochem Behav. 1995; 52(4): 701706.

[80] Enz R, Cutting GR. Molecular composition of GABAC receptors. Vision Res. 1998; 38(10): 1431-1441.

[81] Mody I, Pearce RA. Diversity of inhibitory neurotransmission through GABA(A) receptors. Trends Neurosci. 2004; 27(9): 569575.

[82] Löw K, Crestani F, Keist R, Benke D, Brünig I, Benson JA, et al. Molecular and neuronal substrate for the selective attenuation of anxiety. Science. 2000; 290(5489): 131-134.

[83] McLaughlin KJ, Baran, SE, Conrad CD. Chronic Stress- and SexSpecific Neuromorphological and Functional Changes in Limbic Structures. Mol Neurobiol 2009; 40: 166-182.

[84] Phillips RG, LeDoux JE. Lesions of the fornix but not the entorhinal or perirhinal cortex interfere with contextual fear conditioning. The Journal of Neuroscience. 1995; 15 (7 Pt 2):5308-5315.

[85] Dai X, Thavundayil J, Gianoulakis C. Response of the hypothalamicpituitary-adrenal axis to stress in the absence and presence of ethanol in subjects at high and low risk of alcoholism. Neuropsychopharmacology. 2002; 27(3): 442-452.

[86] Yaribeygi H, Panahi Y, Sahraei H, Johnston TP, Sahebkar A. The impact of stress on body function: A review. EXCLI J. 2017; 16: 1057-1072.

[87] Biagini G, Pich EM, Carani C, Marrama P, Gustafsson JA, Fuxe K, et al. Indole-pyruvic acid, a tryptophan ketoanalogue, antagonizes the endocrine but not the behavioral effects of repeated stress in a model of depression. Biological Psychiatry. 1993; 33(10): 712-719.

[88] Sapolsky RM. Glucocorticoids and hippocampal atrophy in neuropsychiatric disorders. Arch Gen Psychiatry. 2000; 57(10): $925-$ 935.

[89] Lindquist KA, Barrett LF. A functional architecture of the human brain: emerging insights from the science of emotion. Trends Cogn Sci. 2012; 16(11): 533-540.

[90] Amir N, Elias J, Klumpp H, Przeworski A. Attentional bias to threat in social phobia: facilitated processing of threat or difficulty disengaging attention from threat? Behav Res Ther. 2003; 41(11): 13251335.

[91] Gray JA, McNaughton N. The neuropsychology of anxiety: reprise. Nebr Symp Motiv. 1996; 43: 61-134.

[92] Davis M. Neural systems involved in fear and anxiety measured with fear-potentiated startle. Am Psychol. 2006; 61(8): 741-756.

[93] Cacha LA, Poznanski RR. Associable representations as field of influence for dynamic cognitive processes. J Integr Neurosci. 2011; 10(4): 423-437.

[94] Goldstein DS. Adrenal responses to stress. Cell Mol Neurobiol. 2010; 30(8): 1433-1440.

[95] Cavanagh JF, Shackman AJ. Frontal midline theta reflects anxiety and cognitive control: meta-analytic evidence. J Physiol Paris. 2015; 109(1-3): 3-15.

[96] Davis M, Walker DL, Miles L, Grillon C. Phasic vs sustained fear in rats and humans: role of the extended amygdala in fear vs anxiety. Neuropsychopharmacology: Official Publication of the American College of Neuropsychopharmacology. 2010; 35(1): 105-135.

[97] Gaynes BN, Magruder KM, Burns BJ, Wagner HR, Yarnall KS, Broadhead WE. Does a coexisting anxiety disorder predict persistence of depressive illness in primary care patients with major depression? Gen Hosp Psychiatry. 1999;21(3):158-167.

[98] Bach D, Dolan R. Knowing how much you don't know: a neural organization of uncertainty estimates. Nat Rev Neurosci 2012; 13, 572-586.

[99] Paulus MP, Yu AJ. Emotion and decision-making: affect-driven belief systems in anxiety and depression. Trends Cogn Sci. 2012; 16(9): 476-483.

[100] Steimer T. The biology of fear- and anxiety-related behaviors. Dialogues Clin Neurosci. 2002; 4(3): 231-249.

[101] Alexander JL, Dennerstein L, Kotz K, Richardson G. Women, anxiety and mood: a review of nomenclature, comorbidity and epidemiology. Expert Rev Neurother. 2007; 7(11 Suppl): S45-S58.

[102] Lazarus RS. Thoughts on the relations between emotion and cognition. American Psychologist, 1982; 37(9): 1019-1024.

[103] Wittchen HU, Kessler RC, Beesdo K, Krause P, Höfler M, Hoyer J. Generalized anxiety and depression in primary care: prevalence, recognition, and management. J Clin Psychiatry. 2002; 63 Suppl 8: 24-34.

[104] Brown TA, O'Leary TA, Barlow DH. (2001). Generalized anxiety disorder. In Barlow DH (Ed.) Clinical handbook of psychological disorders: A step-by-step treatment manual (pp. 154-208). The Guilford Press.

[105] Gu R, Huang YX, Luo YJ. Anxiety and feedback negativity. Psychophysiology. 2010; 47(5): 961-967.

[106] Kendler KS, Neale MC, Kessler RC, Heath AC, Eaves LJ. Major depression and generalized anxiety disorder. Same genes, (partly) different environments? Arch Gen Psychiatry. 1992; 49(9): 716-722. 